- Advancing Implementation Science: An NCI Perspective, David Chambers, DPhil

- NIH Panel - Interact with NIH leaders and learn how the organization can promote PBRN research: Dr Nicole Redmond, from NHLBI, Dr Eliseo Perez-Stable, from NIMHD; and Dr Wilson Compton, from NIDA

Not surprisingly, this year's pandemic compelled presentations on Covid-19 such as:

- Clinical Trials Recruitment in the COVID-19 Pandemic: Challenges, Opportunities, and a Forum for Sharing Experiences (Braden O'Neill, MD, DPhil, CCFP, \& Aashka Bhatt, BSc).

- The State Networks of Colorado Ambulatory Practices \& Partners (SNOCAP) COVID-19 Crisis Response: One PBRN's Journey to Practice Outreach, Partnership, and Quick Response to the COVID-19 Crisis (Mary Fisher, MPH \& Donald Nease, MD).

- COVID-19 Panel - An Interactive Discussion With Time for Q\&A Around the Latest Developments and Response to the Pandemic (Jack Westfall, MD, MPH, \& Rebecca Etz, PhD).

The 10-member PBRN Planning Committee reviewed over 60 abstracts that covered 15 different themes: behavioral health, chronic care management, clinical practice, community engaged research, dissemination/implementation, health disparities, infrastructure/network operations, practice facilitation/quality improvement, prevention, proposal development/study design/methods, shared decision making/collaborative deliberation, stakeholder engagement, technology, training, Covid-19 responses. The schedule allowed for live, on-demand and interactive sessions, including informal networking over coffee chats and a virtual poster hall. To enhance the experience, some posters were featured in moderated discussions so that attendees could dive deeper into the subject matter and research methodologies.

Presentations remain available for viewing by registered participants on the meeting platform until November 10, 2020 and the American Academy of Family Physicians awarded the conference 8.00 continuing medical education credits.

Stay tuned to NAPCRG's website for information about the 2021 PBRN Conference, which is scheduled to be held in June in Bethesda, Maryland.

Donald Nease, $J r, M D$ Michelle Greiver, MD, MSc

Funding for this conference is made possible [in part] by grant 1R13HSO27067-01 from the Agency for Healthcare Research and Quality (AHRQ). The views expressed in written conference materials or publications and by speakers and moderators do not necessarily reflect the official policies of the Department of Health and Human Services; nor does mention of trade names, commercial practices or organizations imply endorsement by the US Government.

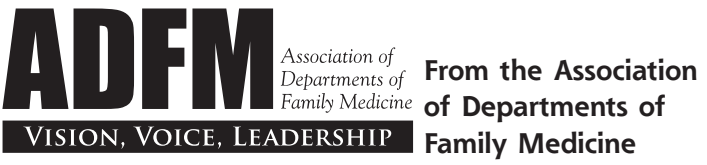

Ann Fam Med 2020;18:570-571. https://doi.org/10.1370/afm.2620.

\section{THE COVID-19 PANDEMIC AND SILVER LININGS FOR PATIENT-CENTERED CARE}

Before the COVID-19 pandemic hit in 2020, the Association of Departments of Family Medicine concluded work in partnership with the Family Medicine for America's Health (FMAHealth) initiative regarding the addition of a public member to its Board of Directors. ${ }^{1,2}$ Through this work, ADFM engaged public and patient members of family medicine organizations' Boards of Directors ${ }^{2}$ to reflect on the intent of these roles in organized family medicine. Underpinning all of the efforts to engage the public and patients in the work of organized family medicine is a conviction to ensure we are putting the patient and welfare of the public and our communities at the center of what we do. An irony reported in 2019 by Stollenwerk et al is that realizing the promise of patient-centered care is easier to articulate than to implement. ${ }^{3}$ This irony has become a new reality as Alexander and Perkins reported in July 2020 with the pandemic providing a stark wake-up call to change care delivery and to change how we train and prepare doctors for the future. ${ }^{4}$ They note that "in response to COVID-19, we and others were able to transform the health care system in a matter of weeks." Meanwhile, Krist, DeVoe and colleagues also reported in July 2020 that primary care had to reinvent itself to protect clinicians and staff and while remaining connected to patients. ${ }^{5}$

The patient and public members of family medicine organizations' Boards engaged in conversations about how these recent realities arising with the advent and progression of COVID-19 are "silver linings" which allow the true patient-centeredness of care to shine through. The COVID-19 pandemic has highlighted how the promise of patient-centered care is not just aspirational. The ways the practice of family medicine has maintained the connection to patients during the chaos of COVID-19, and has highlighted the visibility of the value of this level of patient-centeredness, are noteworthy. Here we share the silver linings that emerged from these conversations as important issues to continue to watch unfold as we all make our way through and out to the other side of this pandemic.

- People are listening. People are listening to primary care in new ways now-we have the opportunity to talk 
about primary care and the importance of keeping our health care workforce intact and safe like never before - Receptivity to change. New and familiar partners are being brought to the table to consider changes in health plans and optimal care of populations and communities, not just individual patients. COVID-19 has pinpointed the criticality, and shortcomings, of care of vulnerable populations.

- Exposure of a broken system. Related to the above point regarding receptivity to change is the way the pandemic has raised the stark, ugly reality of how broken our health care system is. At the root of the problem is how poorly aligned the US business model for health care is with the needs of our populations and communities. In addition to being part of the solution for change, physicians need to fully understand our hospital and procedure-centric business model for health care and why this has failed amidst COVID-19. Physicians need to receive training at all levels about the business of medicine in our country and to use their enhanced knowledge to work toward a more efficient and equitable model. COVID-19 has exposed this potentially critical gap in training and continuing medical education for all physicians.

- Teamwork. A hallmark of primary care, teamwork, has always been an aspirational goal. With COVID-19, teamwork is happening in organic and seamless ways as the altered universe of "normal" has dictated a new level of health professionals working together to care for patients and communities.

- Family as care team member. Through COVID-19, there is a newfound appreciation for the role of the family in the care of patients. With the need for strict policies keeping people away from inpatients during the COVID-19 pandemic, family members/support persons normally critical to care of patients in hospitals are not available to assist with care. This has led some physicians to write orders for a support person to be present in the care of patients.

- Enbanced communication. Communication has been enhanced on multiple levels as all of us respond to the reality of COVID-19. There is the patient-centered level of communication related to translating patient care materials for diverse populations; there is enhanced communication at the organizational level through active use of already existing list-serves and other communication platforms as leaders learn from one another about on-the-ground challenges and solutions; there is the enhanced ability for collaboration among professionals in organizational conversations through the onset of virtual meetings, with unprecedented frequency and utility.

A final and concluding point is that these conversations with public and private members took place before there was subsequent heightened awareness of racial injustice in our country. Many of the "silver linings" touched on here are part and parcel with health equity. As Alexander and Perkins note, in this time of forced change, "why not create something better than normal?"4 The true realization of these "silver linings" will be the lasting change brought about by institutionalizing the ones which truly lead to a more just and equitable system of care and a safer world for all.

Ardis Davis, Amanda Weidner, Julie Moretz, Ned Holland, with acknowledgement of contributions from conversations with other family medicine public and patient members Beth Bortz and Arturo Martinez-Guijosa

\footnotetext{
References

1. Grumbach K, Gilchrist V, Davis AK, et al. ADFM and FMAHealth boards' engagement around a public member pilot study. Ann Fam Med. 2018;16(2):182-183.

2. Davis A, Gilchrist V, Moretz J, Weidner A, Grumbach K, Holland K. What ADFM learned from bringing a public member onto its board of directors. Ann Fam Med. 2020;18(5):472-473.

3. Stollenwerk D, Kennedy LB, Hughes LS, O'Connor M. A systematic approach to understanding and implementing patient-centered care. Fam Med. 2019;51(2):173-178.

4. Alexander C, Perkins RA. On miracles and moving on. Ann Fam Med. 2020;18(4):376-378.

5. Krist AH, DeVoe JE, Cheng A, Ehrlich T, Jones SM. Redesigning primary care to address the COVID-19 pandemic in the midst of the pandemic. Ann Fam Med. 2020;18(4):349-354.
}
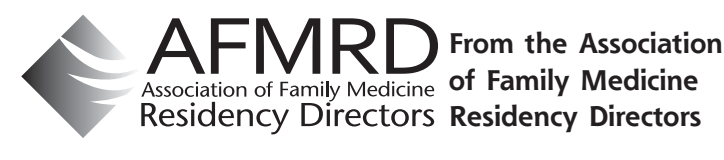

Ann Fam Med 2020;18:571-572. https://doi.org/10.1370/afm.2621.

\section{REFLECTIONS OF THREE HEALTH EQUITY FELLOWS}

The Association of Family Medicine Residency Directors (AFMRD) is committed to delivering Health Equity education to residency directors and faculty. Over the past year, the AFMRD sponsored 3 individuals for the 2019-2020 AAFP Health Equity Fellowship. This yearlong fellowship develops family physicians into leaders with expertise in the social, institutional, and cultural influences that impact health. Fellows also complete a capstone project to demonstrate their achievement of the program's learning objectives.

The 3 fellows shared a brief summary of their experience in the fellowship.

\section{Debra A. Rothenberg, MD}

I came to medicine via the Peace Corps in Niger and then studying anthropology and have spent most of 